\title{
Irrigação e fertirrigação potássica na cultura da videira em condições semiáridas ${ }^{1}$
}

\author{
André Henrique Pinheiro Albuquerque ${ }^{2}$, Thales Vinicius de Araújo Viana ${ }^{2}$, \\ Albanise Barbosa Marinho ${ }^{3}$, Geocleber Gomes de Sousa ${ }^{2}$, Benito Moreira de Azevedo ${ }^{2}$
}

\begin{abstract}
Potassium irrigation and fertigation of grapevine under semiarid conditions

The potassium irrigation management and fertigation adjustment may improve grape yield and quality. Aiming at evaluating the biometric and productive characteristics of the 'Ribier' grapevine, under five irrigation levels (50\%, 75\%, 100\%, $125 \%$ and $150 \%$ of the class A pan evaporation - CAE) and five potassium fertilization doses (2, 4, 6, 8 and 10 days), applied by fertigation, two experiments were carried out in a randomized blocks design, with five treatments and five replications, in Limoeiro do Norte, Ceará State, Brazil. The variables bunch number, size and average weight, soluble solids and yield were evaluated for the five irrigation levels, while the bunch average weight and width, number of berries, soluble solids and yield were evaluated for the five potassium fertigation intervals. The maximum irrigation level (150\% of the CAE) and the seven days interval for the potassium fertigations provided the best yield for the 'Ribier' grapevine, under the Ceará State semiarid conditions.
\end{abstract}

KEY-WORDS: Vitis vinifera L.; water deficit; fruit quality.

\section{INTRODUÇÃO}

A área mundial cultivada com a videira é de 7,1 milhões de hectares, com produção aproximada de 70 milhões de toneladas (FAO 2011). Em 2011, a área plantada com videira, no Brasil, era de 84,3 mil hectares, com produção de 1,5 milhões de toneladas (IBGE 2012). No semiárido brasileiro, a produção de uva vem apresentando grande expansão, pois, nesta região, fatores como luminosidade e temperatura favorecem a produção desta cultura durante todo o ano e com excelente qualidade de cachos.

A viticultura envolve práticas de manejo de irrigação e de adubação potássica adequadas, em todas

\section{RESUMO}

O manejo da irrigação e o ajuste da fertirrigação potássica podem melhorar a produtividade e qualidade de frutos da cultura da uva. Com o objetivo de avaliar as características biométricas e produtivas da videira 'Ribier', sob cinco níveis de irrigação $(50 \%, 75 \%, 100 \%, 125 \%$ e $150 \%$ de evaporação do tanque classe A - ECA) e cinco parcelamentos de adubação potássica (2, 4, 6, 8 e 10 dias), aplicados via fertirrigação, foram realizados dois experimentos, com delineamento de blocos ao acaso, com cinco tratamentos e cinco repetições, em Limoeiro do Norte (CE). Foram analisadas as variáveis número, tamanho e massa média de cachos, sólidos solúveis e produtividade, para os cinco níveis de irrigação, e massa média e largura dos cachos, número de bagas, sólidos solúveis e produtividade, para os cinco intervalos de fertirrigação potássica. O máximo nível de irrigação (150\% da ECA) e o intervalo de sete dias entre fertirrigações potássicas proporcionaram o melhor desempenho produtivo da variedade 'Ribier', nas condições do semiárido cearense.

PALAVRAS-CHAVE: Vitis vinifera L.; déficit hídrico; qualidade de frutos.

as fases do seu ciclo de desenvolvimento. De acordo com Azevedo \& Bezerra (2008), o uso de diferentes lâminas de irrigação é uma maneira bastante prática para estimar as necessidades hídricas de uma espécie cultivada, para que a cultura possa se desenvolver e produzir de maneira adequada.

A aplicação de água em excesso proporciona aumento nos custos de produção, além de causar risco de lixiviação da água e de nutrientes nela diluídos, para regiões abaixo da profundidade efetiva do sistema radicular (Aurora et al. 2011). Porém, o déficit hídrico é fator limitante para a obtenção de elevadas produtividades, sendo que a duração e a época de sua ocorrência afetam, em maior ou menor intensidade,

1. Trabalho recebido em dez./2012 e aceito para publicação em set./2013 ( $n^{\circ}$ registro: PAT 21386).

2. Universidade Federal do Ceará (UFC), Centro de Ciências Agrárias, Departamento de Engenharia Agrícola, Fortaleza, CE,

Brasil.E-mails: andrehenrique84@yahoo.com.br, thales@ufc.br, sousamsa@yahoo.com.br, benitoazevedo@hotmail.com.

3. Universidade da Integração Internacional da Lusofonia Afrobrasileira (Unilab), Campus da Liberdade, Redenção, CE, Brasil.

E-mail: albanise@unilab.edu.br. 
o rendimento das culturas no campo (Ahmadia et al. 2011, Braga Filho et al. 2011).

Prado (2008) afirma que a adubação potássica é importante para a formação de carboidratos nas folhas e tem papel fundamental na translocação destes assimilados para as diversas partes da planta, principalmente os frutos, demonstrando uma relação com os teores de açúcares totais presentes na uva e o acúmulo de reservas nutricionais nas bagas.

Uma alternativa para minimizar as perdas da adubação potássica é o uso da fertirrigação. Seu emprego possibilita a otimização do uso de insumos, tanto em aspectos relacionados à produtividade quanto à qualidade final dos produtos obtidos, sendo mais comum sua adoção em culturas irrigadas por sistemas localizados, principalmente o sistema por gotejamento (Oliveira \& Villas Bôas 2008).

Outra maneira de minimizar as perdas de nutrientes na agricultura irrigada é o parcelamento de fertilizantes via fertirrigação, promovendo menores perdas e melhor adaptação às condições tropicais (Neves et al. 2009, Vasconcelos et al. 2013). Karasawa et al. (2002) afirmam que o parcelamento da fertirrigação deve ser baseado na periodicidade da irrigação, sendo que os intervalos entre irrigações não podem ser muito curtos, pois favorecem o desenvolvimento radicular superficial. De acordo com Andrade Júnior et al. (2007), o parcelamento da adubação potássica aumenta a eficiência de uso do fertilizante, reduzindo suas perdas por lixiviação.

Considerando-se a importância da viticultura no cenário brasileiro e a expansão de sua demanda, e buscando-se a melhoria do seu sistema produtivo, este trabalho objetivou avaliar as características biométricas e produtivas da videira, sob níveis de irrigação e intervalos de fertirrigação potássica, aplicados via fertirrigação.

\section{MATERIAL E MÉTODOS}

O trabalho foi desenvolvido em área experimental da agroempresa Frutacor, localizada no município de Limoeiro do Norte (CE) $\left(05^{\circ} 06^{\prime} \mathrm{S}\right.$, $37^{\circ} 52^{\prime} \mathrm{W}$ ), de setembro de 2008 a janeiro de 2009. O clima da região, de acordo com a classificação de Köppen, é do tipo BSw'h' (semiárido, com máximo de chuvas no outono e muito quente). O solo da área é classificado como Cambissolo Háplico (Santos et al. 2006).
O experimento foi instalado em uma área de $1.152 \mathrm{~m}^{2}(15,0 \mathrm{~m} \times 76,8 \mathrm{~m})$, cultivada com videira da variedade 'Ribier', com cinco anos de idade, plantada com espaçamento de 2,4 m x 3,0 m entre plantas e fileiras, respectivamente, e enxertada sobre a cultivar IAC 572 'Jales'. A irrigação foi realizada com gotejadores autocompensantes da Netafim, que operavam com vazão média de $24 \mathrm{~L} \mathrm{~h}^{-1}$ planta $^{-1}$.

Foram realizados dois experimentos, em delineamento experimental em blocos casualizados, com cinco tratamentos e cinco repetições, com quatro plantas úteis por unidade experimental. $\mathrm{O}$ primeiro experimento avaliou o manejo da irrigação e foi constituído por cinco lâminas, determinadas em função da evapotranspiração do tanque classe $\mathrm{A}(\mathrm{ECA}): \mathrm{N} 1=50 \%$; N2 = 75\%; N3 = 100\%; N4 = $125 \%$; N5 $=150 \%$.

Buscando-se estabelecer uniformidade no estande, nos quinze primeiros dias após a poda (DAP), todos os tratamentos foram irrigados diariamente com a mesma lâmina (equivalente a 100\% da ECA). Após este período, os níveis de irrigação passaram a ser aplicados de acordo com cada um dos cinco tratamentos (N1 a N5).

No segundo experimento, que avaliou o manejo da fertirrigação potássica, os tratamentos foram cinco intervalos de fertirrigação $(2,4,6,8$ e 10 dias $)$, com cinco repetições.

A fonte potássica utilizada foi o sulfato de potássio diluído por fertirrigação, de acordo com a recomendação da análise de solo para o ciclo completo da cultura (110 dias), seguindo-se recomendações de Fernandes (1993). A aplicação da fertirrigação iniciou-se no $15^{\circ}$ DAP. Apesar do intervalo diferenciado, o total por ciclo foi equivalente entre os tratamentos (368 kg ha-1 de $\left.\mathrm{K}_{2} \mathrm{O}\right)$.

As colheitas dos experimentos foram realizadas após amostragens no campo, para a determinação do teor de sólidos solúveis totais, que deve ser, em sua maioria, igual ou superior a $15^{\circ}$ Brix (Brasil 2002). Constatando-se que os cachos estavam prontos para a colheita, dividiu-se a copa de cada planta em quatro quadrantes e retirou-se um cacho representativo de cada quadrante.

No ato da colheita, os cachos colhidos dos quadrantes foram contados e, logo após, medidos e pesados, separadamente para cada tratamento e repetição, sendo avaliadas as seguintes variáveis biométricas: número de cachos por planta $(\mathrm{NC})$, número de bagas (NB), comprimento dos cachos (CC), largura 
dos cachos (LC), teor de sólidos solúveis (SS), massa média dos cachos (MMC) e produtividade (PROD).

Para a quantificação dos cachos, realizou-se, antes da colheita, a contagem dos mesmos, em todas as plantas úteis. A massa média dos cachos foi obtida pesando-se os cachos colhidos, com o auxílio de uma balança eletrônica (Digipeso, modelo DP-15) com precisão de $1,0 \mathrm{~g}$. As variáveis tamanho e largura dos cachos foram determinadas com o auxílio de um paquímetro digital (Digimess) e o teor de sólidos solúveis em refratômetro ocular (Alla France). A produtividade foi determinada por meio dos dados das variáveis NC e MMC, utilizando-se a equação $\mathrm{PROD}=\mathrm{NC} \times \mathrm{MMC} \times 1.388,89 \times(1 / 1.000 .000), \mathrm{em}$ que PROD é a produtividade, em $\mathrm{kg} \mathrm{ha}^{-1} \mathrm{ciclo}^{-1} ; \mathrm{NC}$ o número de cachos, em unidade de cacho; MMC a massa média dos cachos, em g; 1.388,89 a quantidade de plantas por hectare; e (1/1.000.000) uma constante para transformar grama em megagrama $(\mathrm{Mg})$.

De posse dos dados, foi realizada a análise de variância, para cada variável estudada. Posteriormente, quando significativos pelo teste $\mathrm{F}$, a $1 \%$ ou $5 \%$, os dados foram submetidos à análise de regressão, selecionando-se os modelos que apresentaram os melhores níveis de significância, coeficiente de determinação $\left(\mathrm{R}^{2}\right)$ e significado biológico. Para a realização das análises, utilizou-se o programa computacional Saeg (Ribeiro Júnior 2001).

\section{RESULTADOS E DISCUSSÃO}

Pela análise estatística, foram observadas diferenças significativas para os componentes de produtividade da cultura da uva submetida a diferentes intervalos de fertirrigação potássica. A partir da análise de regressão, verificou-se que a massa média dos cachos, em função dos intervalos de fertirrigação potássica, se ajustou a um modelo polinomial quadrático, com $\mathrm{R}^{2}=0,89$. Por meio do modelo, estimou-se que o intervalo máximo de fertirrigação potássica que proporciona a maior massa média dos cachos $(216,8 \mathrm{~g})$ foi de, aproximadamente, sete dias (6,54 dias) (Figura 1a).

É importante destacar que fertirrigações com intervalos superiores a sete dias aumentam a possibilidade de que a planta não absorva todo o adubo, com consequente lixiviação acelerada do mesmo, levando à diminuição no rendimento das culturas, devido à incapacidade da planta para absorver todo o nutriente aplicado ao solo (Vasconcelos et al. 2013).
Maiores intervalos de fertirrigação tendem a reduzir a disponibilidade dos nutrientes, ocasionando reduções no crescimento e distribuição do sistema radicular, no desenvolvimento da parte aérea e na composição dos frutos (Prado 2008, Viana et al. 2008). Teixeira et al. (2011) obtiveram resultados inferiores ao deste estudo $(4,8 \mathrm{~g})$, ao adubar a cultura da uva cultivar 'Niágara Rosada' com $135 \mathrm{~kg} \mathrm{ha}^{-1} \mathrm{de}_{2} \mathrm{O}$.

Verificou-se, também, que o comprimento dos cachos, em função dos intervalos de fertirrigação potássica, ajustou-se a um modelo polinomial quadrático, com $\mathrm{R}^{2}=0,85$, estimando-se que o intervalo
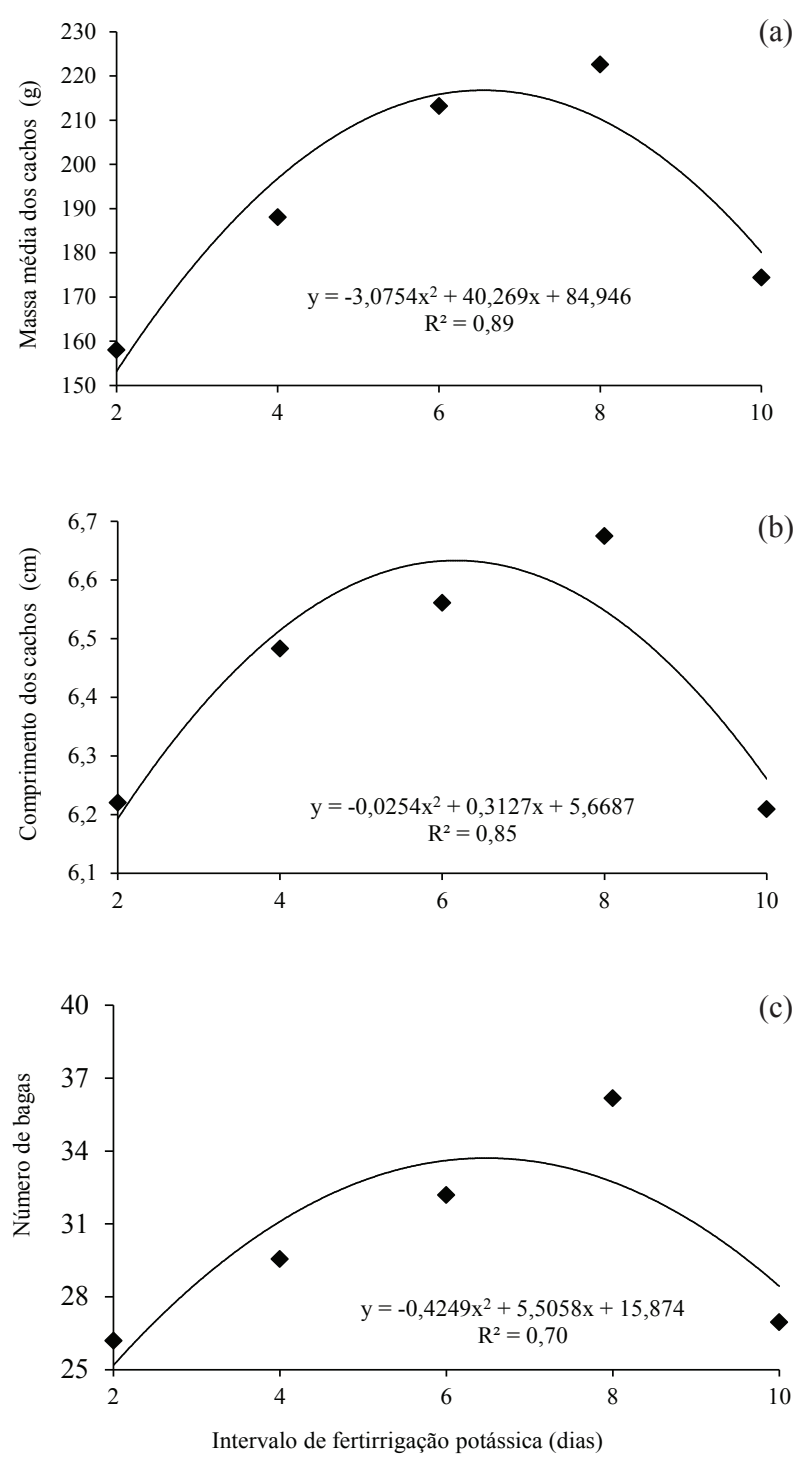

Figura 1. Massa média (a) e comprimento (b) dos cachos e produtividade (c) da videira 'Ribier', sob diferentes intervalos de fertirrigação potássica (Limoeiro do Norte, CE, 2009). 
ótimo de fertirrigação potássica em torno de seis dias (6,26 dias) foi o que proporcionou o maior comprimento dos cachos (Figura 1b).

Esses resultados reforçam a hipótese de Andrade Júnior et al. (2007), de que intervalos maiores implicam em maiores quantidades de fertilizantes sendo aplicadas por vez, podendo acarretar na elevação do potencial osmótico do solo, menor disponibilidade de água para a cultura e consequente redução no crescimento dos frutos, tanto no tamanho como na largura.

Respostas não significativas de doses de potássio $\left(0 \mathrm{~kg} \mathrm{ha}^{-1}, 45 \mathrm{~kg} \mathrm{ha}^{-1}, 90 \mathrm{~kg} \mathrm{ha}^{-1}\right.$ e $135 \mathrm{~kg} \mathrm{ha}^{-1}$ de $\mathrm{K}_{2} \mathrm{O}$ ) sobre o comprimento dos cachos, em videira 'Niágara Rosada', durante quatro ciclos, em Louveira (SP), foram observadas por Teixeira et al. (2011).

O aumento no intervalo de fertirrigação potássica exerceu efeito significativo sobre o número de bagas da videira (Figura 1c), sendo que o modelo polinomial quadrático foi o mais adequado, com $\mathrm{R}^{2}=0,70$. Por meio do modelo, estimou-se que o intervalo ótimo de fertirrigação potássica que maximizou o número de bagas foi de, aproximadamente, sete dias (6,78 dias).

A redução no número de bagas pode ter ocorrido devido ao fato de que, nas fertirrigações mais frequentes (em pequenos intervalos de tempo, como, por exemplo, a cada 2 dias), o adubo é mais diluído, facilitando a lixiviação do mesmo. Em oposição, quando se utilizam fertirrigações menos frequentes (em maiores intervalos de tempo, como, por exemplo, a cada 10 dias), aumenta-se a possibilidade de que a planta não absorva todo o adubo, com consequente lixiviação do mesmo.

Teixeira et al. (2011) também constataram reduções nas características biométricas, decorrentes do excesso de adubação nos vinhedos. Tal excesso de adubação pode ser encontrado ao se aplicar maiores intervalos de fertirrigação. Do mesmo modo, segundo Coelho et al. (2004), intervalos maiores de fertirrigação podem levar a um crescimento inferior das culturas, devido à incapacidade da planta para absorver todo o nutriente aplicado ao solo.

A produtividade não foi alterada pelo aumento nos intervalos de fertirrigação potássica (Figura 2a). Este resultado pode ser atribuído aos problemas na absorção de cálcio e magnésio, decorrentes do fracionamento da aplicação do potássio. Tendência similar foi reportada por Teixeira et al. (2011), avaliando as alterações em atributos químicos do solo causadas pela adubação com diferentes doses de K (45 kg ha-1,

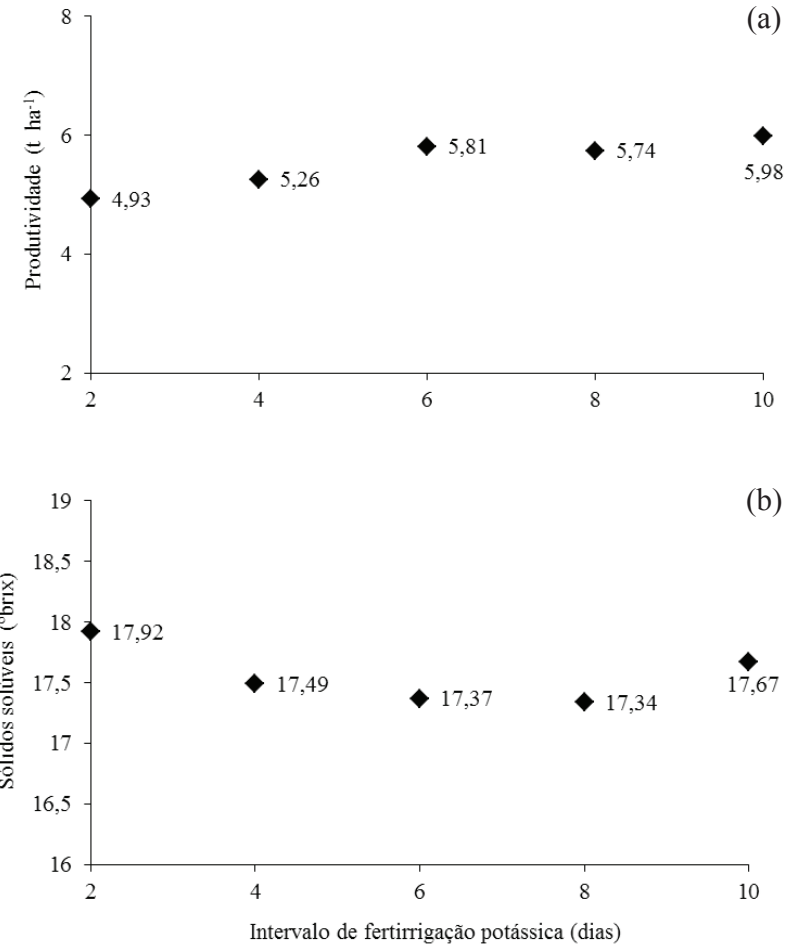

Figura 2. Produtividade (a) e teor de sólidos solúveis totais (b) da videira 'Ribier', sob diferentes intervalos de fertirrigação potássica (Limoeiro do Norte, CE, 2011).

$90 \mathrm{~kg} \mathrm{ha}^{-1}$ e $135 \mathrm{~kg} \mathrm{ha}^{-1}$ de $\mathrm{K}_{2} \mathrm{O}$ ), aplicadas de forma convencional à videira 'Niágara Rosada'.

Outra explicação está na lixiviação do K, com a aplicação simultânea deste elemento mineral via água de irrigação (Sousa et al. 2013), onde a disponibilidade de K para as plantas depende muito da sua difusão no solo (Neves et al. 2009), uma vez que a quantidade que chega às raízes por fluxo de massa é muito menor que a taxa de absorção.

O teor de sólidos solúveis totais também não foi alterado com o aumento no intervalo de fertirrigação potássica (Figura 2b). Cabe destacar que os valores de sólidos solúveis obtidos neste trabalho estão dentro da faixa considera ótima, para a cultura da videira ( $16^{\circ}$ Brix) (Soares \& Leão 2009).

Com relação ao experimento 2, verificou-se que o modelo linear crescente foi o mais adequado para explicar a variação no número de cachos (NC), em função das lâminas de irrigação. O máximo valor observado para o NC $(36,99)$ foi obtido sob o nível de irrigação de $150 \%$ da ECA, com $\mathrm{R}^{2}=0,89$ (Figura 3a). Este comportamento, provavelmente, pode estar relacionado à característica genética da planta, textura do solo e às condições climáticas da região de estudo. 
Bassoi et al. (2011) verificaram que o manejo de irrigação com déficit hídrico, a partir da fase fenológica, reduziu o número de cachos da videira cultivar 'Niágara Rosada', nas condições edafoclimáticas de Petrolina (PE). Do mesmo modo, Serman et al. (2004), em experimento com a cultivar apirênica 'Superior Seedless' irrigada sob diferentes percentagens da evapotranspiração, observaram diminuição no número de cachos comercializáveis, nos tratamentos com déficit hídrico.

O aumento da disponibilidade hídrica proporcionou aumentos lineares no comprimento de cachos, com $\mathrm{R}^{2}=0,81$ (Figura 3b). É importante destacar que o déficit de água, durante as primeiras semanas após a frutificação, provoca reduções no comprimento do cacho da videira, afetando-o, de forma irreversível, mesmo que haja umedecimento após o período de estiagem (Bassoi et al. 2011).

Observou-se redução linear para os sólidos solúveis, de acordo com os níveis de irrigação (Figura 3c). O máximo valor de sólidos solúveis observado $\left(17,8^{\circ} \mathrm{Brix}\right)$ foi obtido sob o nível de irrigação de $50 \%$ da ECA. No entanto, para todos os níveis de irrigação estudados, os valores de SS estão dentro dos padrões mínimos praticados na comercialização dos frutos, ou seja, $15^{\circ}$ Brix (Brasil 2002).
Resultados similares foram observados por Busato et al. (2011), ao irrigarem a cultivar 'Niágara Rosada' com reposição de $33 \%$ da lâmina de irrigação, em um período de quatro anos. Semelhantemente, Marinho et. al. (2009) constataram que as maiores lâminas de irrigação proporcionaram menores valores de sólidos solúveis. Estes autores relatam, ainda, que este efeito pode estar relacionado ao aumento do teor de água nos frutos, tornando os açúcares mais diluídos nos frutos.

O modelo linear crescente foi o mais adequado $\left(\mathrm{R}^{2}=0,91\right)$ para a variável produtividade (Figura $\left.3 \mathrm{~d}\right)$. O máximo valor da produtividade $\left(11,70 \mathrm{t} \mathrm{ha}^{-1}\right)$ foi obtido sob o nível de irrigação de $150 \%$ da ECA, correspondente a uma lâmina de $1.290 \mathrm{~mm} \mathrm{ciclo}^{-1}$. A produtividade obtida entre os tratamentos está abaixo da média do Ceará $\left(23,6 \mathrm{t} \mathrm{ha}^{-1}\right)$ e da média nacional $\left(18,2 \mathrm{t} \mathrm{ha}^{-1}\right)$ (IBGE 2011). Este resultado mostra que a variedade 'Ribier', quando irrigada nas condições edafoclimáticas da região semiárida, necessita de maior lâmina de irrigação, para atingir o ponto máximo de produtividade. Busato et al. (2011), analisando o manejo da irrigação, com base na umidade do solo, nas condições climáticas de Colatina (ES), com a cultivar 'Niágara Rosada', verificaram produtividade inferior à deste estudo $\left(6,7 \mathrm{tha}^{-1}\right)$.
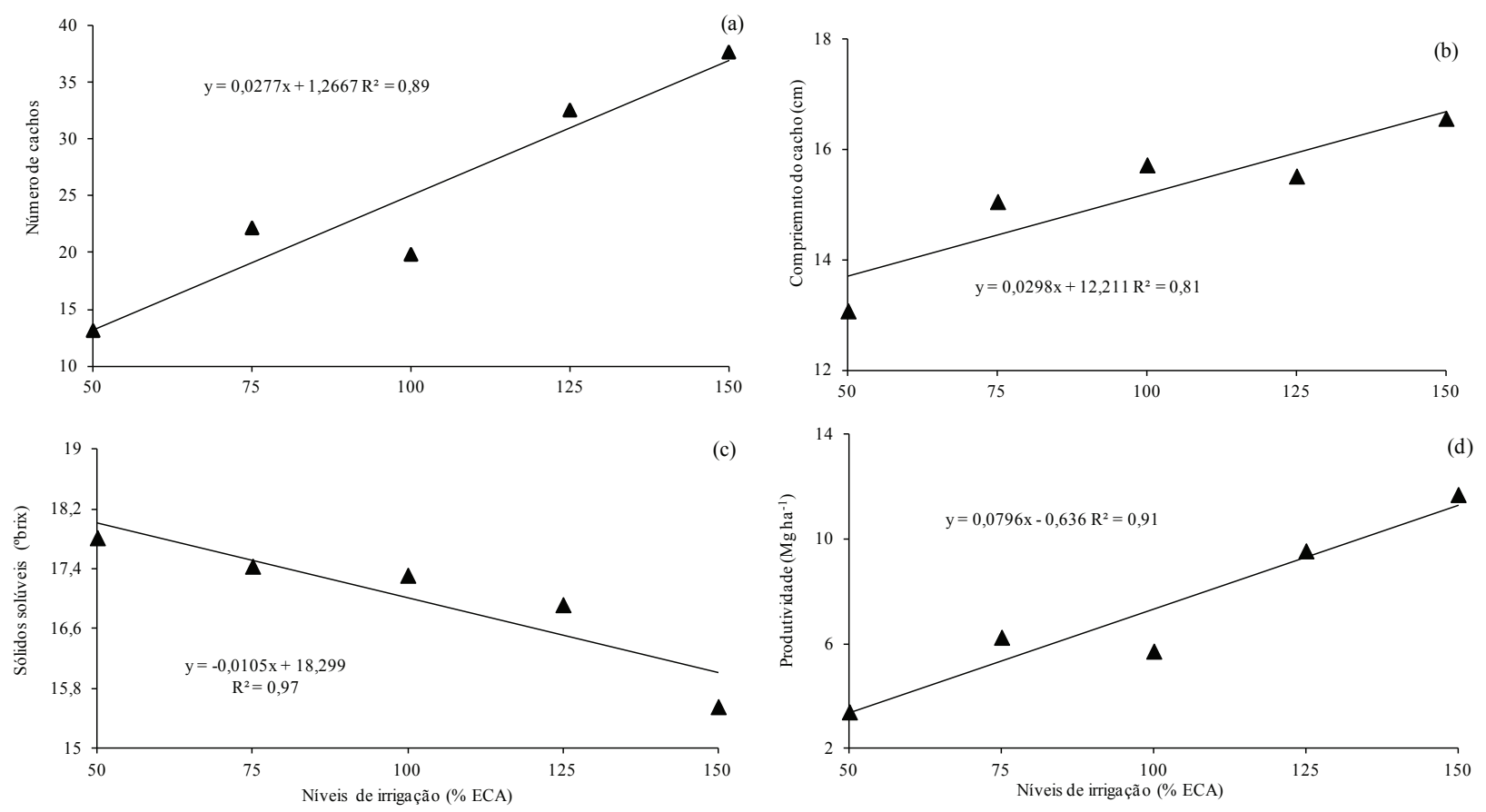

Figura 3. Número (a) e comprimento (b) de cachos, sólidos solúveis (c) e produtividade (d) da videira 'Ribier', sob diferentes níveis de irrigação (Limoeiro do Norte, CE, 2009). 
Marinho et al. (2009) afirmam que o déficit hídrico, na fase de maturação da uva cultivar 'Superior Seedless', no semiárido baiano, aos 21 dias antes da colheita, não evidenciaram redução na produtividade da uva. O mesmo comportamento foi obtido para ervilhas, por Oliveira et al. (2011), que verificaram que a lâmina excessiva pode afetar a produtividade. Por outro lado, um déficit hídrico muito severo pode afetar, negativamente, a produtividade e a qualidade da uva (Netzer et al. 2009, Sousa et al. 2013).

\section{CONCLUSÃO}

O máximo nível de irrigação (150\% da ECA) e o intervalo de sete dias entre fertirrigações potássicas proporcionaram o melhor desempenho produtivo da variedade 'Ribier', nas condições do semiárido cearense.

\section{REFERÊNCIAS}

AHMADIA, S. H. et al. Effects of irrigation strategies and soils on field grown potatoes: root distribution. Agricultural Water Management, Amsterdam, v. 98, n. 8, p. 1280-1290, 2011.

ANDRADE JÚNIOR, A. S. et al. Frequência de aplicação de nitrogênio e de potássio via água de irrigação por gotejamento na cultura da melancia em Parnaíba, PI. Agropecuária Científica no Semiárido, Patos, v. 3, n. 1, p. 1-7, 2007.

AURORA, V. K. et al. Irrigation, tillage and mulching effects on soybean yield and water productivity in relation to soil texture. Agricultural Water Management, Amsterdam, v. 98, n. 4, p. 563-568, 2011.

AZEVEDO, J. H. O.; BEZERRA, F. M. L. Resposta de dois cultivares de bananeira a diferentes lâminas de irrigação. Revista Ciência Agronômica, Fortaleza, v. 39, n. 1, p. 28-33, 2008.

BASSOI, L. H. et al. Influência de manejos de irrigação sobre aspectos de ecofisiologia e de produção da videira cv. Syrah/Paulsen 1103. Revista Irriga, Botucatu, v. 16, n. 4, p. 395-402, 2011.

BRAGA FILHO, J. R. et al. Lâminas de irrigação e genótipos na produção e qualidade de frutos de bananeira. Pesquisa Agropecuária Tropical, Goiânia, v. 41, n. 2, p. 155-162, 2011.

BRASIL. Ministério da Agricultura, Pecuária e Abastecimento. Instrução normativa $n .{ }^{\circ} 1$, de 01 de fevereiro de 2002. Regulamenta a classificação e padronização de uvas rústicas e híbridas de mesa. Brasília, DF: MAPA/SARC, 2002.

BUSATO, C. C. M. et al. Manejo da irrigação e fertirrigação com nitrogênio sobre as características químicas da videira 'Niágara Rosada'. Ciência Rural, Santa Maria, v. 41, n. 7, p. 1183-1188, 2011.

COELHO, E. F. et al. Fontes e frequências de aplicação de nitrogênio via água de irrigação no mamoeiro. 2004. Disponível em: <http://www.cnpmf.embrapa.br/ publicacoes/comunicados/comunicado_111.pdf $>$. Acesso em: 18 jul. 2007.

FERNANDES, V. L. B. Recomendações de adubação e calagem para o Estado do Ceará. Fortaleza: UFC, 1993.

FOOD AND AGRICULTURE ORGANIZATION OF THE UNITED NATIONS (FAO). Faostat agriculture. 2011. Disponível em: $<\mathrm{http}: / /$ faostat.fao.org $>$. Acesso em: 19 dez. 2011.

INSTITUTO BRASILEIRO DE GEOGRAFIA E ESTATÍSTICA (IBGE). Sistema IBGE de recuperação automática (Sidra): produção agrícola municipal 2008. 2011. Disponível em: <http://www.sidra.ibge.gov.br/bda/ tabela/listabl.asp? $\mathrm{c}=1613 \& \mathrm{z}=\mathrm{p} \& \mathrm{o}=18>$. Acesso em: 20 out. 2011.

INSTITUTO BRASILEIRO DE GEOGRAFIA E ESTATÍSTICA (IBGE). Sistema IBGE de recuperação automática (Sidra): produção agrícola municipal 2011. 2012. Disponível em: <http://www.sidra.ibge.gov.br/ bda/tabela/listabl.asp? $\mathrm{c}=1613 \& \mathrm{z}=\mathrm{p} \& \mathrm{o}=18>$. Acesso em: 25 set. 2012.

KARASAWA, S.; FARIA, M. A.; GUIMARÃES, R. J. Influência da irrigação e do parcelamento de fertirrigação sobre a produtividade, rendimento e qualidade do café (Coffea arabica L. cv. Topázio mg-1190). Ciência e Agrotecnologia, Lavras, n. esp., p. 1427-1438, 2002.

MARINHO, L. B. et al. Produção e qualidade da videira 'Superior Seedless' sob restrição hídrica na fase de maturação. Pesquisa Agropecuária Brasileira, Brasília, DF, v. 44, n. 12, p. 1682-1691, 2009.

NETZER, Y.; YAO, C.; SHENKER, M. Water use and the development of seasonal crop coefficients for Superior Seedless grapevines trained to an open-gable trellis system. Irrigation Science, Prague, v. 27, n. 2, p. 109-120, 2009.

NEVES, L. S.; ERNANI, P. R.; SIMONETE, M. A. Mobilidade de potássio em solos decorrente da adição de doses de cloreto de potássio. Revista Brasileira de Ciência do Solo, Viçosa, v. 33, n. 1, p. 25-32, 2009.

OLIVEIRA, E. C. et al. Viabilidade técnica e econômica da produção de ervilha (Pisum sativum L.) cultivada sob diferentes lâminas de irrigação. Engenharia Agrícola, Piracicaba, v. 31, n. 2, p. 324-333, 2011. 
OLIVEIRA, M. V. A. M.; VILlAS BÔAS, R. L. Uniformidade de distribuição do potássio e do nitrogênio em sistema de irrigação por gotejamento. Engenharia Agrícola, Jaboticabal, v. 28, n. 1, p. 95-103, 2008.

PRADO, R. M. Nutrição de plantas. São Paulo: Unesp, 2008.

RIBEIRO JÚNIOR, J. I. Análises estatísticas no Saeg. Viçosa: UFV, 2001.

SANTOS, H. G. et al. (Eds.). Sistema brasileiro de classificação de solos. 2. ed. Rio de Janeiro: Embrapa Solos, 2006.

SERMAN, F. V.; LIOTTA, M.; PARERA, C. Effects of irrigation deficit on table grape cv. Superior Seedless production. Acta Horticulturae, Amsterdam, n. 646, p. 183-186, 2004.

SOARES, J. M.; LEÃO, P. C. de S. A vitivinicultura no semiárido brasileiro. Brasília, DF: Embrapa Informação Tecnológica; Petrolina: Embrapa Semiárido, 2009.
SOUSA, G. G. et al. Adubação potássica aplicada por fertirrigação e pelo método convencional na cultura do amendoim. Revista Brasileira de Engenharia Agrícola e Ambiental, Campina Grande, v. 17, n. 10, p. 1055-1060, 2013.

TEIXEIRA, L. A. J. et al. Alterações em atributos químicos de um solo submetido à adubação e cultivado com videira 'Niágara Rosada'. Revista Brasileira de Fruticultura, Jaboticabal, v. 33, n. 3, p. 983-992, 2011.

VASCONCELOS, D. V. et al. Interação entre níveis de irrigação e fertirrigação potássica na cultura do maracujazeiro. Irriga, Botucatu, v. 18, n. 1, p. 160-170, 2013.

VIANA, T. V. et al. Diferentes doses de potássio, na forma de nitrato de potássio, aplicadas via fertirrigação no mamão Formosa. Revista Ciência Agronômica, Fortaleza, v. 39, n. 1, p. 34-38, 2008. 